\title{
Downregulation of Clusterin Expression in Human Testicular Seminoma
}

\author{
Bianjiang Liu Min Tang Zhijian Han Jiexiu Zhang Pei Lu Jie Li Ninghong Song \\ Zengjun Wang Changjun Yin Wei Zhang
}

State Key Laboratory of Reproductive Medicine and Department of Urology, The First Affiliated Hospital of Nanjing Medical University, Nanjing, China

\author{
Key Words \\ Clusterin • Expression • Testicular seminoma
}

\begin{abstract}
Background: Clusterin, a heterodimeric glycoprotein of approximately $80 \mathrm{kDa}$, exists extensively in human body fluids. The abnormal expression of clusterin is closely related to the occurrence, progression, and prognosis of tumors. Up to now, few studies have focused on clusterin in human testicular cancer. This study describes an extensive exploration of the presence and expression of clusterin in testicular seminoma. Methods: Tumor tissues and normal testis tissues were collected from 13 patients with testicular seminoma and 16 patients undergoing surgical castration for prostate cancer. Real-time polymerase chain reaction (PCR) was performed to detect the expression difference of clusterin mRNA between testicular seminoma and normal testis. Western blot and immunohistochemical analysis were performed to detect the presence and expression difference of clusterin protein between two groups. Results: Real-time PCR showed the expression of clusterin mRNA in testicular seminoma to be significantly lower than in normal testis (only $13 \%$ relative quantification). Western blot analysis indicated marked reductions in the expression of clusterin protein in testicular seminoma. Similar results were observed upon immunohistochemical analysis. Conclusion: In testicular seminoma and normal testis, clusterin exists in its heterodimeric secretory isoform. Clusterin expression is significantly lower in testicular seminoma than in normal testis. This is the first comprehensive study of the presence and expression of clusterin in human testicular cancer.
\end{abstract}




\section{Introduction}

Clusterin is a heterodimeric glycoprotein of approximately $80 \mathrm{kDa}$. It contains $\alpha$ and $\beta$ subunits with similar molecular weight. It exists extensively in human body fluids, such as cerebrospinal fluid, breast milk, blood, urine, and semen [1]. Clusterin was initially identified from ram rete testis fluid and named for its ability to enhance the clustering of Sertoli cells [2]. Clusterin plays important roles in many pathophysiological processes, such as atherosclerosis, neurodegeneration, and tissue injury [3]. Abnormal expression of clusterin is closely related to the occurrence, progression, and prognosis of tumors. Although several previous reports have shown the overexpression of clusterin in tumors, recent studies demonstrated that clusterin is down-regulated in cancers with different genetic backgrounds $[4,5]$. One possible function of clusterin is to protect tumor cells from apoptosis and damage caused by autoimmunity or anti-tumor therapy $[1,5]$. In this way, clusterin is considered an indicator of tumorigenesis, progression, and prognosis.

In a previous series of studies, we continuously researched the presence, localization and function of clusterin in male genital tract $[6,7]$. We detected abundant clusterin protein in normal human testis [7]. One previous work reported the downregulation of clusterin expression in human testicular cancer using immunohistochemisty [8]. This is the only existing previous study of clusterin in testicular cancer. Testicular cancer is the most common solid tumor in 15-30 year-old men [9]. About 40\% of testicular cancer is seminoma, the most common germ cell cancer [9]. Seminoma is more sensitive to radiotherapy and chemotherapy than other male urogenital cancers. The protection from apoptosis and antitumor therapy that clusterin provides to tumor cells renders its expression characteristics and functions highly relevant. This study describes an extensive investigation of the presence and expression of clusterin in human testicular seminoma.

\section{Materials and Methods}

Approval for this study was granted by the ethics committee of Nanjing Medical University (China) prior to sample collection and informed written consent was received from all participants. All chemicals and reagents used in this study were molecular biology grade and purchased from Sigma-Aldrich (St. Louis, MO, U.S.) unless otherwise stated.

\section{Samples collection}

Tissues samples were collected from 29 patients at our center from October 2001 to October 2011. The average age of 13 patients with testicular seminoma was $34 \pm 4.0$ (range 21-43) years. They received orchiectomy for testicular masses and were diagnosed with seminoma in a final pathologic examination. For the normal control group, 16 patients with prostate cancer were recruited. The average age was $70.5 \pm 1.9$ (range 65-81) years. They underwent surgical castration. Postoperative pathologic results showed no obvious abnormality in resected testes. All samples except histological sections were immediately stored at $-80{ }^{\circ} \mathrm{C}$ until use.

\section{RNA extraction and reverse transcription}

Testis tissue was homogenized by grinding in liquid nitrogen and total RNA was extracted using an RNeasy Mini Kit (Qiagen; Dusseldorf, Nordrhein-Westfalen, Germany) according to the manufacturer's instructions. RNA samples were quantified using a DU800 spectrophotometer (Beckman Coulter; S. Kraemer Boulevard Brea, CA, U.S.). Aliquots of total RNA from each sample were reverse-transcribed to cDNA using a ReverTra Ace ${ }^{\circledR}$ qPCR RT Kit (TOYOBO; Osaka, Japan) according to the manufacturer's instructions as our previous report [10].

Real-time PCR was performed on an Applied Biosystems® 7300 Real-Time PCR System (Life Technologies; Carlsbad, CA, U.S.). $\beta$-actin served as an internal control. Primer sequences were shown 
Table 1. Primer sequences for Real-time PCR

\begin{tabular}{lcc}
\hline Gene & & Sequence $\left(5^{\prime}-3^{\prime}\right)$ \\
\hline clusterin & forward & ATTCATACGAGAAGGCGACG \\
& reverse & CAGCGACCTGGAGGGATT \\
$\beta$-actin & forward & GAAATCGTGCGTGACATTAA \\
& reverse & AAGGAAGGCTGGAAGAGTG \\
\hline
\end{tabular}

in Table 1. The reaction solution contained $6.4 \mu \mathrm{l}$ of $\mathrm{ddH}_{2} \mathrm{O}, 10 \mu \mathrm{l}$ of $\mathrm{SYBR}^{\circledR}$ Green Real-time PCR Master Mix (TOYOBO; Osaka, Japan), 8 pmol of forward and reverse primers, and $2 \mu \mathrm{l}$ of cDNA. Amplification was performed at $95^{\circ} \mathrm{C}$ for $3 \mathrm{~min}$, followed by 40 cycles at $95^{\circ} \mathrm{C}$ for $10 \mathrm{~s}$, then at $60{ }^{\circ} \mathrm{C}$ for $30 \mathrm{~s}$, and finally at 72 ${ }^{\circ} \mathrm{C}$ for $45 \mathrm{~s}$. The cycle numbers where the amplification curve crossed the threshold were noted as $\mathrm{C}_{\mathrm{T}}$ values. Three replicates of each reaction were performed and the $\mathrm{C}_{\mathrm{T}}$ values were averaged. The relative amount of clusterin expression as normalized to $\beta$-actin was calculated using $2^{-\Delta C}{ }_{T}$, where $\Delta C_{T}=\left(C_{T^{\prime}}\right.$ clusterin $-C_{T^{\prime}} \beta$-actin $)$. The relative difference of clusterin gene expression between testicular seminoma and normal testis and was calculated using $2^{-\Delta \Delta C}$ method.

\section{Western blot analysis}

Testis tissue was homogenized by grinding in liquid nitrogen and protein was extracted using RIPA Lysis Buffer (Beyotime biotechnology; Shanghai, China). After centrifugation at $12000 \mathrm{~g}$ for $10 \mathrm{~min}$ at $4{ }^{\circ} \mathrm{C}$, the supernatant was collected and stored at $-80{ }^{\circ} \mathrm{C}$ until use. The protein concentration was measured in a bicinchoninic acid assay. Aliquots of protein were boiled in sodium dodecyl sulphate (SDS)-PAGE sample buffer, resolved using polyacrylamide gels, and transferred onto polyvinylidene fluoride membrane (BioRad, Hercules, CA, U.S.) using a Semi-Dry Transfer Unit (GE Healthcare, Piscataway, NJ, U.S.). The membrane was blocked in Tris-buffered saline (TBS) containing 5\% non-fat milk for $1 \mathrm{~h}$, incubated with mouse antihuman clusterin antibody or with normal mouse IgG as the control (1:1000; Abcam; Cambridge, Cambs, U.K.) overnight at $4{ }^{\circ} \mathrm{C}$, washed in TBS, and probed with horseradish peroxidase (HRP) conjugated goat anti-mouse IgG (1:2000; Beijing ZhongShan Biotechnology; Beijing, China) for $1 \mathrm{~h}$ at $37^{\circ} \mathrm{C}$. The blotted proteins were detected using a FluorChem System (ProteinSimple, Santa Clara, CA, U.S.) and an Enhanced Chemoluminescence Kit (GE Healthcare, Piscataway, NJ, U.S.).

\section{Immunohistochemistry}

Formalin-fixed testis tissue was embedded in paraffin, sectioned at $5 \mu \mathrm{m}$ and mounted on silane-coated slides. Sections were de-waxed and re-hydrated through descending grades of alcohol to distilled water. Slides were subjected to microwave antigen retrieval in $0.02 \mathrm{M}$ EDTA and incubated in $3 \% \mathrm{H}_{2} \mathrm{O}_{2}$ to block endogenous peroxidase. Then the sections were washed in PBS, blocked with goat serum for 15 min at room temperature, and incubated with mouse anti-human clusterin antibody or with normal mouse IgG, which served as a control, in a humidified chamber overnight at $4{ }^{\circ} \mathrm{C}(1: 200$; Abcam; Cambridge, Cambs, U.K.). After washing in phosphate-buffered saline, slides were incubated with biotin-conjugated goat anti-mouse IgG for $15 \mathrm{~min}$ at $37^{\circ} \mathrm{C}$, followed by incubation with a streptavidin/peroxidase complex for $15 \mathrm{~min}$ at 37 ${ }^{\circ} \mathrm{C}$. Immunoreactivity was evaluated with 3,3'-diaminobenzidine (DAB). Sections were counterstained with hematoxylin, mounted onto coverslips and observed using Olympus CX31 Binocular Microscope (Olympus; Tokyo, Japan).

\section{Statistical analysis}

Data were expressed as mean \pm SD. T-test was performed for the comparison of two groups. Statistically significant differences were determined at $\mathrm{P}<0.05$. 
Table 2. The relative difference of clusterin gene expression between testicular seminoma and normal testis. Data were shown as Mean \pm SD

\begin{tabular}{cccc}
\hline & $\Delta \mathrm{C}_{\mathrm{T}}$ & $\Delta \Delta \mathrm{C}_{\mathrm{T}}$ & $2^{-\Delta \Delta_{\mathrm{T}}}$ \\
\hline Seminoma & $2.42 \pm 1.16$ & $3.00 \pm 0.75$ & $0.13(0.07-0.21)$ \\
Normal & $-0.58 \pm 0.34$ & $0.00 \pm 0.34$ & $1(0.79-1.27)$ \\
\hline
\end{tabular}

Fig. 1. Expression of clusterin mRNA normalized to $\beta$-actin in testicular seminoma and normal testis. Data were shown as Mean \pm SD. $*$ : $\mathrm{P}<0.05$.

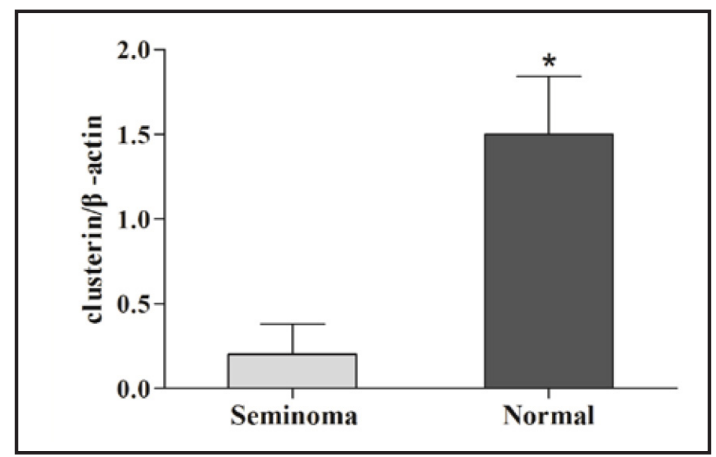

Fig. 2. Expression of clusterin protein in normal testis and testicular seminoma. Lane 1 and 3: normal testis; Lane 2 and 4: testicular seminoma. M: marker. A representative experiment was shown.

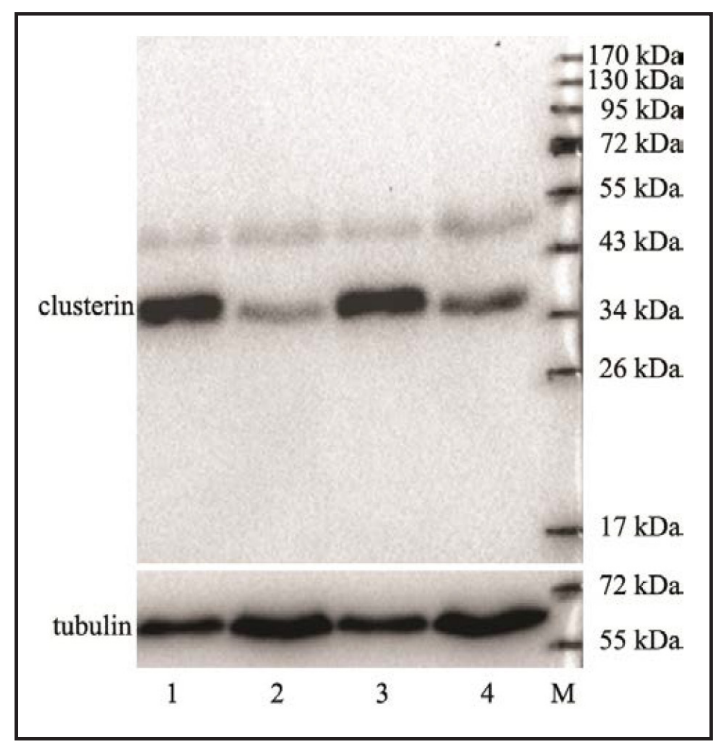

\section{Results}

\section{Real-time PCR}

Clusterin mRNA was successfully amplified from testicular seminoma and normal testis. However, the relative expression amount of clusterin gene normalized by $\beta$-actin in testicular seminoma was significantly lower than in normal testis (Fig. 1). Further relative quantification analysis showed the same results (Table 2). The expression of clusterin gene in testicular seminoma was only $13 \%$ of that in normal testis.

\section{Western blot analysis}

Western blot analysis was performed to determine the expression characteristics and possible differences between testicular seminoma and normal testis at the protein level. As shown in Fig. 2, the obvious $\sim 40 \mathrm{kDa}$ bands were probed with specific anti-clusterin antibody in all samples. Protein expression was significantly lower in testicular seminoma than in normal testis (Fig. 2). 


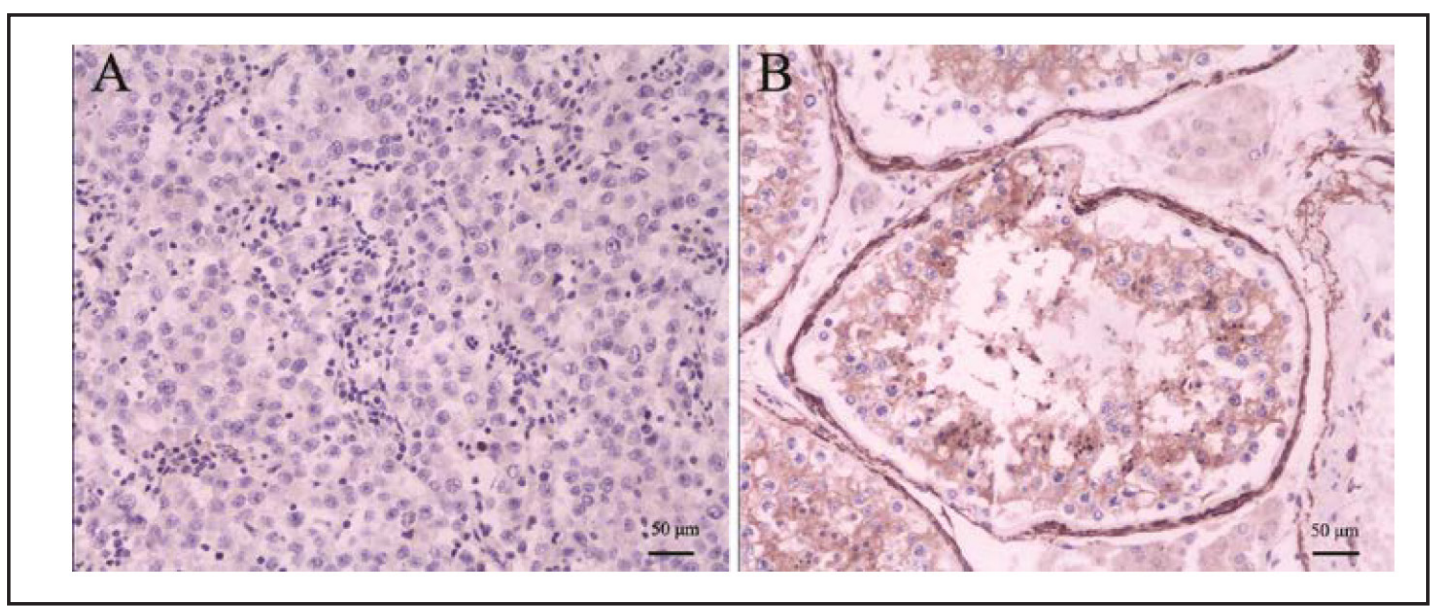

Fig. 3. Immunohistochemical expression and localization of clusterin protein in testicular seminoma and normal testis. A: no obvious staining was observed in testicular seminoma. B: intense staining (brown) was observed in normal testis, especially in Leydig cells, Sertoli cells, and mature spermatogenic cells. A representative experiment was shown. Magnification was $\times 200$.

\section{Immunohistochemistry}

The expression and localization of clusterin in testicular tissues were observed by immunohistochemistry. As shown in Fig. 3A, no obvious staining existed in testicular seminoma. However, intense staining (brown) was observed in normal testis, especially in Leydig cells, Sertoli cells, and mature spermatogenic cells (Fig. 3B).

\section{Discussion}

There are two major isoforms of clusterin: secretory clusterin and nuclear clusterin. Secretory clusterin is synthesized, targeted to the endoplasmic reticulum, glycosylated and proteolytically cleaved into $\alpha$ and $\beta$ subunits with similar molecular weight, and held together by disulfide bonds $[11,12]$. The mature secretory clusterin found in body fluids is an $\sim 80$ $\mathrm{kDa}$ heterodimeric glycoprotein. Few studies focus on nuclear clusterin, which is a stress induced protein. It is localized in the cytoplasm as an $\sim 49 \mathrm{kDa}$ inactive protein precursor without $\alpha / \beta$ cleavage [12]. After cytotoxic events, nuclear clusterin moves into the nucleus and acts as an $\sim 55 \mathrm{kDa}$ cell death protein $[12,13]$. In our present study, the obvious $\sim 40 \mathrm{kDa}$ bands detected by western blot analysis under reducing conditions suggested that clusterin in testis tissues was heterodimeric secretory clusterin. The significant downregulation of clusterin expression in testicular seminoma was confirmed at the gene transcription and protein expression levels. The present work is the first comprehensive study of the presence and expression of clusterin in human testicular cancer.

The abnormal expression of clusterin exists in various types of cancers. The expression can even differ across different developmental stages of the same tumor. Clusterin expression is widely considered to be down-regulated in vast majority of tumors, especially during the early stage of the disease $[4,5]$. This downregulation may promote tumorigenesis and metastasis. Several recent studies have shown that genetic inactivation of clusterin can promote tumorigenesis and metastasis $[14,15]$. In addition, clusterin represents a positive biomarker of better overall survival [16-18]. These data suggest that clusterin is a tumor suppressor. However, upregulation of clusterin expression has been observed in advanced tumors or tumors subjected to anti-tumor therapy (radiotherapy and chemotherapy) [4,17]. The antisense oligonucleotides of clusterin increased the tumor's sensitivity to radiotherapy and chemotherapy $[4,19]$. It has been hypothesized that up-regulation of clusterin may confer resistance to treatments through protection of tumor cells from damage caused by 
anti-tumor therapy $[4,5,17]$. These findings indicate that the roles of clusterin in tumors are more complex than anticipated.

Although abnormal expression of clusterin has been shown to participate in the occurrence, progression and prognosis of tumors, the exact molecular mechanism is controversial. As a tumor modifier, clusterin may interfere with several signaling pathways mediated by NF- $\kappa B$, PI3 kinase, or MAP kinase [5, 15, 18]. A few studies have focused on nuclear clusterin, a cell death protein that plays a pro-apoptotic role [11-13]. The possible functions of nuclear clusterin in tumors merit further study.

In conclusion, the present study focuses extensively on the presence and expression characteristics of clusterin in human testicular seminoma. In testicular seminoma, clusterin is present as a heterodimeric secretory isoform. Clusterin expression is significantly downregulated in testicular seminoma than in normal testis. Testicular seminoma is one of the most sensitive tumors to radiotherapy and chemotherapy. Clusterin can protect tumor cells from damage caused by anti-tumor therapy. This renders the relationship between clusterin and human testicular seminoma highly relevant. In further study, we will continue to research this protein through in vitro observation of the response of tumor cells to treatments under conditions that will alter the expression and function of clusterin. The expression and roles of clusterin in other types of testicular cancers also merit further study.

\section{Conflict of Interest}

The authors declare no conflict of interest.

\section{Acknowledgements}

This work is supported by a grant from National Natural Science Foundation of China (81200467) and by A Project Funded by the Priority Academic Program Development of Jiangsu Higher Education Institutions (JX10231801).

\section{References}

1 Trougakos IP, Gonos ES: Clusterin/apolipoprotein J in human aging and cancer. Int J Biochem Cell Biol 2002;34:1430-1438.

$>2$ Blaschuk 0, Burdzy K, Fritz IB: Purification and characterization of a cell-aggregating factor (clusterin), the major glycoprotein in ram rete testis fluid. J Biol Chem 1983;258:7714-7720.

-3 Calero M, Rostagno A, Frangione B, Ghiso J: Clusterin and Alzheimer's disease. Subcell Biochem 2005;38:273-298.

4 Miyake H, Hara I, Gleave ME: Antisense oligodeoxynucleotide therapy targeting clusterin gene for prostate cancer: Vancouver experience from discovery to clinic. Int J Urol 2005;12:785-794.

5 Sala A, Bettuzzi S, Pucci S, Chayka O, Dews M, Thomas-Tikhonenko A: Regulation of CLU gene expression by oncogenes and epigenetic factors implications for tumorigenesis. Adv Cancer Res. 2009;105:115-132.

6 Wang Z, Widgren EE, Richardson RT, O’Rand MG: Characterization of an eppin protein complex from human semen and spermatozoa. Biol Reprod 2007;77:476-484.

7 Han Z, Wang Z, Cheng G, Liu B, Li P, Li J, Wang W, Yin C, Zhang W: Presence, localization, and origin of clusterin in normal human spermatozoa. J Assist Reprod Genet 2012;29:751-757.

8 Behrens P, Jeske W, Wernert N, Wellmann A: Downregulation of clusterin expression in testicular germ cell tumours. Pathobiology 2001;69:19-23. 
-9 Schmoll HJ, Jordan K, Huddart R, Laguna MP, Horwich A, Fizazi K, Kataja V; ESMO Guidelines Working Group: Testicular seminoma: ESMO clinical recommendations for diagnosis, treatment and follow-up. Ann Oncol 2009;20:S83-88.

10 Liu B, Wang P, Wang Z, Jia Y, Niu X, Wang W, Zhang W: Analysis and difference of voltage-dependent anion channel mRNA in ejaculated spermatozoa from normozoospermic fertile donors and infertile patients with idiopathic asthenozoospermia. J Assist Reprod Genet 2010;27:719-724.

11 Leskov KS, Klokov DY, Li J, Kinsella TJ, Boothman DA: Synthesis and functional analyses of nuclear clusterin, a cell death protein. J Biol Chem 2003;278:11590-11600.

-12 Yang CR, Leskov K, Hosley-Eberlein K, Criswell T, Pink JJ, Kinsella TJ, Boothman DA: Nuclear clusterin/XIP8, an x-ray-induced Ku70-binding protein that signals cell death. Proc Natl Acad Sci USA 2000;97:5907-5912.

13 Bettuzzi S, Rizzi F: Nuclear CLU (nCLU) and the fate of the cell. Adv Cancer Res 2009;104:59-88.

14 Chayka O, Corvetta D, Dews M, Caccamo AE, Piotrowska I, Santilli G, Gibson S, Sebire NJ, Himoudi N, Hogarty MD, Anderson J, Bettuzzi S, Thomas-Tikhonenko A, Sala A: Clusterin, a haploinsufficient tumor suppressor gene in neuroblastomas. J Natl Cancer Inst 2009;101:663-677.

15 Bettuzzi S, Davalli P, Davoli S, Chayka O, Rizzi F, Belloni L, Pellacani D, Fregni G, Astancolle S, Fassan M, Corti A, Baffa R, Sala A: Genetic inactivation of ApoJ/clusterin: effects on prostate tumourigenesis and metastatic spread. Oncogene 2009;28:4344-4352.

16 Xie MJ, Motoo Y, Su SB, Mouri H, Ohtsubo K, Matsubara F, Sawabu N: Expression of clusterin in human pancreatic cancer. Pancreas 2002;25:234-238.

17 Panico F, Rizzi F, Fabbri LM, Bettuzzi S, Luppi F: Clusterin (CLU) and lung cancer. Adv Cancer Res 2009;105:63-76.

18 Panico F, Casali C, Rossi G, Rizzi F, Morandi U, Bettuzzi S, Davalli P, Corbetta L, Storelli ES, Corti A, Fabbri LM, Astancolle S, Luppi F: Prognostic role of clusterin in resected adenocarcinomas of the lung. Lung Cancer 2013;79:294-299.

19 Zellweger T, Miyake H, July LV, Akbari M, Kiyama S, Gleave ME: Chemosensitization of human renal cell cancer using antisense oligonucleotides targeting the antiapoptotic gene clusterin. Neoplasia 2001;3:360367. 